\title{
Sustaining the Fight against Tobacco Industries to Attain Permanent Benefits
}

\section{Saurabh RamBihariLal Shrivastava* and Shrivastava PS}

Department of Community Medicine, Shri Sathya Sai Medical College and Research Institute, Tamil Nadu, India

\section{Introduction}

Tobacco and its products have been linked with the deaths of more than 7 million people on an annual basis, of which close to $87 \%$ deaths have been attributed to direct use of them, while the remaining have been attributed to second-hand smoke [1]. It is an alarming fact that in excess of $50 \%$ of the users are dying because of the tobacco, which is a real cause of global public health concern $[1,2]$. Moreover, it becomes even more difficult as four-fifths of the world's smokers are from developing nations, which are already having a weak public health care delivery system, inadequate health care financing and limited resources [1].

In order to deal with the existing global public health menace of tobacco, wide range of strategies have been tried upon, with the varied extent of success [2-6]. Interventions in the form of pictorial warnings on the tobacco products; anti-tobacco advertisements \& use of mass media; prohibition of tobacco advertisements, promotion and sponsorship (67\% of the global nations have successfully done it); and an increase in the taxes over tobacco products, has been implemented in different nations [3-5]. However, it is really surprising that despite the availability of documented evidence (viz. a $10 \%$ decrease in the tobacco products, will reduce the consumption of tobacco by $4 \%$ in developed and 5\% in developing nations), a meager 33 nations have introduced the provision [1,2].

In addition, significant emphasis has been given to bring an end to the illicit trade of tobacco products by targeting the responsible agencies involved in smuggling, illicit production and counterfeiting [6]. At this juncture, it is important to understand that even though tobacco industries have expressed their support to curb illicit practices, however in reality, their stand has been quite different [7]. Moreover, in one of the recent developments, the tobacco industry in the United States has been forced to accept that their products are harmful and they have misled the general population about the health benefits of smoking [7].
Furthermore, in a latest resolution, the French bank has decided to no longer finance and invest in tobacco companies [7]. However, we must not be too happy with these developments and not think that the war against the industry is over, as these industries will definitely come up with some new ways to oppose the imposed restrictions or by the launch of some other types of products [7]. There is an immense need to strongly implement the World Health Organization's Framework Convention on Tobacco Control [1-6].

To conclude, the need of the hour is to ensure that all the national governments should come forward and continue the momentum against tobacco industries and continue their intensified support to enforce prohibition of advertisement, promotion, production and marketing related activities.

\section{References}

1. World Health Organization (2017) Tobacco - Fact sheet No: 339.

2. Shrivastava SR, Shrivastava PS, Ramasamy J (2017) Ensuring tobacco control to strengthen the economy of a nation and improve the health standards of the population. Int J Prev Med 8: 94.

3. Shrivastava SR, Shrivastava PS, Ramasamy J (2017) Discouraging the practice of tobacco initiation among children and adolescents through promotion of smoke-free films. Int J Prev Med 8: 34.

4. Shrivastava SR, Shrivastava PS, Ramasamy J (2016) Envisaging plain packaging of tobacco products: Appeal to national policy makers. Int J Prev Med 7:131.

5. Shrivastava SR, Shrivastava PS, Ramasamy J (2017) Implementing mTobacco Cessation program in India to assist users in quitting tobacco: World Health Organization. Ann Trop Med Public Health 10: 1417-1418.

6. Shrivastava SR, Shrivastava PS, Ramasamy J (2016) World Health Organization calls for curbing illicit tobacco trade market. Ann Trop Med Public Health 9: 124-125.

7. Ghebreyesus TA, Vázquez TR (2017) Seeing through big tobacco's smokescreen.

*Corresponding author: Saurabh RamBihariLal S, Department of Community Medicine, Shri Sathya Sai Medical College and Research Institute, Tamil Nadu, India, Tel: 919884227224; Email: drshrishri2008@gmail.com

Received February 09, 2018; Accepted February 13, 2018; Published February 20, 2018

Citation: Shrivastava SR, Shrivastava PS (2018) Sustaining the Fight against Tobacco Industries to Attain Permanent Benefits. Prim Health Care 8: e123. doi: 10.4172/2167-1079.1000e123

Copyright: ( 2018 Shrivastava SR, et al. This is an open-access article distributed under the terms of the Creative Commons Attribution License, which permits unrestricted use, distribution, and reproduction in any medium, provided the original author and source are credited. 